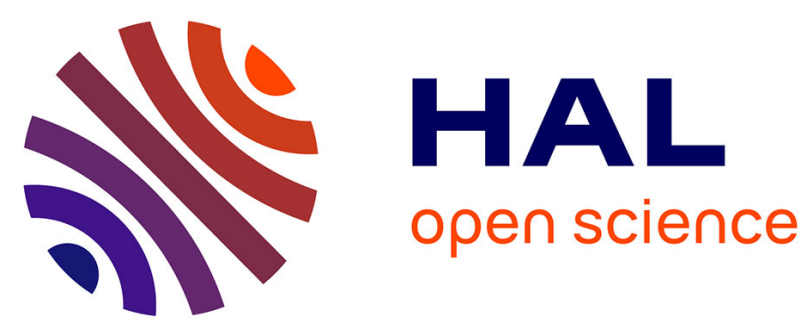

\title{
A picture's worth a thousand words: speckle tracking for quantification and assessment of lung sliding
}

\author{
Gary Duclos, Laurent Muller, Marc Leone, Laurent Zieleskiewicz
}

\section{To cite this version:}

Gary Duclos, Laurent Muller, Marc Leone, Laurent Zieleskiewicz. A picture's worth a thousand words: speckle tracking for quantification and assessment of lung sliding. Intensive Care Medicine, 2018, 45 (1), pp.101-102. 10.1007/s00134-018-5303-9 . hal-02084809

\section{HAL Id: hal-02084809 \\ https://hal-amu.archives-ouvertes.fr/hal-02084809}

Submitted on 29 Mar 2019

HAL is a multi-disciplinary open access archive for the deposit and dissemination of scientific research documents, whether they are published or not. The documents may come from teaching and research institutions in France or abroad, or from public or private research centers.
L'archive ouverte pluridisciplinaire HAL, est destinée au dépôt et à la diffusion de documents scientifiques de niveau recherche, publiés ou non, émanant des établissements d'enseignement et de recherche français ou étrangers, des laboratoires publics ou privés. 


\section{A picture's worth thousand words: Speckle tracking for quantifying lung sliding}

Lung sliding assessment and quantification with speckle tracking technology.

Gary DUCLOS $^{1 *}$, MD; Laurent MULLER ${ }^{2}$, PhD; Marc LEONE ${ }^{3}$, PhD; Laurent ZIELESKIEWICZ4, MD.

* Corresponding author : Gary DUCLOS ; gary.duclos@ap-hm.fr +330491965377; Service d'Anesthésie et de Réanimation, Hôpital Nord, Chemin des Bourrely, 13015 Marseille.

${ }^{1}$ Aix Marseille Université, Assistance Publique Hôpitaux de Marseille, Service d'Anesthésie et de Réanimation, Hôpital Nord, Marseille, France. Gary.duclos@ap-hm.fr

${ }^{2}$ Département d'anesthésie réanimation et médecine d'urgence, CHU Nîmes Caremeau, Nîmes, France. Laurent.muller@chu-nimes.fr

${ }^{3}$ Aix Marseille Université, Assistance Publique Hôpitaux de Marseille, Service d'Anesthésie et de Réanimation, Hôpital Nord, Marseille, France. Marc.leone@ap-hm.fr

${ }^{4}$ Aix Marseille Université, C2VN, Assistance Publique Hôpitaux de Marseille, Service d'Anesthésie et de Réanimation, Hôpital Nord, Marseille, France. Laurent.zieleskiewicz@aphm.fr

Dr Gary DUCLOS, Laurent MULLER and Marc LEONE denied any conflict of interest regarding this article.

Dr Laurent ZIELESKIEWICZ declares having received fees for ultrasound teaching for General Electrics healthcare.

The present manuscript was written under acceptance of the concerned patient. 
A 19 years-old female admitted to our intensive care unit for a blunt chest trauma due to road traffic accident. The whole-body computed tomography scan revealed left side costal fractures and a left pneumothorax. Two days after pleural drainage, chest tube was set in gravity causing a decrease in oxygen saturation. We performed a lung ultrasound examination with linear probe (4 MHZ) from Vivid IQ (General Electrics, Chicago, Illinois, USA). Due to the poor echogenicity, we used a speckle tracking evaluation in order to quantify lung sliding in spontaneous breathing (Figure 1). Hence, the quantification of lung sliding is feasible with an important ratio (x10) between normal and abolished lung sliding during spontaneous breathing. To our knowledge, this case is the first assessment of lung sliding using speckle tracking technology. Lung sliding assessment can be challenging in B-mode ultrasonography. Its quantification with speckle tracking technology could help for the diagnosis of pneumothorax, opening new perspectives in the field of lung ultrasound.

Figure 1

The figure presents speckle tracking of segmental longitudinal strain and M-Mode lung ultrasonography from contralateral (normal) lung (A) and left (blunted) lung with a lung-point view (B) and a pneumothorax view (C). Upper side of the picture shows maximal longitudinal strain value of 3 segments (yellow, blue and green). Middle side of the picture shows longitudinal strain variations during respiratory cycle of each segment symbolized with a curve of the corresponding color (yellow, blue or green). Low side of the picture shows MMode evaluation of pleural sliding on the same lung ultrasound view.

Normal lung evaluation (longitudinal scan) (A) shows maximal longitudinal strain segmental values of around 10 symmetric segmental curves after respiratory cycle and a classic lung sliding or "seashore sign" picture in M-Mode. Lung point view (transversal scan) (B) shows a normal longitudinal strain value of yellow segment (sliding lung) and low values of blue and green segment (the pneumothorax part of the view) with their respective curves. M-mode 
shows the sequence of a typical "stratosphere sign" (abolition of lung sliding) with a normal lung sliding image ("seashore sign"). Pneumothorax view (longitudinal scan) (C) shows altered longitudinal strain value for all segments with associated curves showing no variation during respiratory cycle. M-Mode shows absence of lung sliding ("stratosphere sign"). 